\title{
Increasing radiation power in half width microstrip leaky wave antenna by using slots technique
}

\author{
Muhannad Kaml Abdulhameed ${ }^{1}$, Sarah Rafil Hashim ${ }^{2}$, Noor Kamil Abdalhameed ${ }^{3}$, \\ Ahmed Jamal Abdullah Al-Gburi ${ }^{4}$ \\ ${ }^{1}$ Information Technology Department, University of Kerbala, Karbala, Iraq \\ ${ }^{2}$ Faculty of Education, Al-Zahraa University for Women, Karbala, Iraq \\ ${ }^{3}$ Faculty of Medicine, University of Warith Al-Anbiyaa, Karbala, Iraq \\ ${ }^{4}$ Faculty of Electronics and Computer Engineering, Universiti Teknikal Malaysia Melaka (UTeM) Durian Tunggal, Melaka, Malaysia
}

\begin{abstract}
Article Info
Article history:

Received Mar 18, 2021

Revised Jun 18, 2021

Accepted Jun 29, 2021

Keywords:

Cross-polarization

HW-MLWA

LWA

Radiation power

ABSTRACT

The radiation power in the endfire is decreased while the main beam of half substrate integrated waveguide scan from broadside to endfire in a forward. The design of half-width microstrip leaky-wave antenna (HW-MLWA) has been presented in this work to increase the power radiation near endfire by using the slots technique in the radiation element. This slot leads to a decrease the cross-polarization. The proposed design comprises one element of HWMLWA with repeated meandered square slots in the radiation element. One aspect of this antenna is generated by using a half substrate integrated waveguide with a full tapered feed line. The proposed antenna was terminated by load of $50 \Omega$, and feed on the other end of the antenna. Finally, the suggested design is simulated and acceptable results were found. The released gain is increased from $10.6 \mathrm{dBi}$ to $12 \mathrm{dBi}$ at $4.3 \mathrm{GHz}$. This design is suitable for unmanned aerial vehicle UAVs at $\mathrm{C}$ band application.
\end{abstract}

Slots technique
This is an open access article under the $\mathrm{CCBY-SA}$ license.

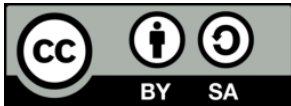

\section{Corresponding Author:}

Muhannad Kaml Abdulhameed

Department of Information Technology, College of Computer Science and Information Technology

University of Kerbala

Karbala, Iraq

Email: muhannad.k@uokerbala.edu.iq

\section{INTRODUCTION}

The invention of microwave technology related to linear leaky wave antennas can be used in radio engineering systems, including air traffic control systems, communications, radar, and radio navigation, based on both stationary and mobile objects, including aircraft. The first idea of leaky-wave antenna (LWA) introduced in 1978 with explaining the first higher-order mode for electromagnetic wave [1]-[3]. The planner low-profile antenna structure depending on the half-width microstrip leaky-wave antenna, become an attractive best choice for the researchers [4], [5]. The half-width microstrip leaky-wave antenna (HW-MLWA) is suitable for most applications, for example, point to multipoint communications, automotive aircraft radar. Most of the radiation leaky-wave antenna has been controlled by varying the operation frequency deadening of the frequency bands [6]-[8]. The direction of the beam scanning is directed by changing the operation frequency. The equation of the direct beam steering of the leaky-wave antenna is assumed by [9], [10]. Where $\theta(f)$ is the broadside angle, $k_{o}$ is the wavenumber, and $\beta$ is defined as the phase constant. So, the varying of the effective phase constant lead to varying of the main beam because of the change in the reactance of profile antenna [11]-[13].

$$
\theta(f)=\sin ^{-1}\left[\frac{\beta(f)}{k_{o}(f)}\right]
$$


The beam steering or scanning technique in most communication systems depends on the changing of operating frequency [14]. However, some methods of control radiation pattern by changing the feed position of the microstrip line. The radiation pattern is changed by using the slot technique. The radiation pattern control in the half-width microstrip LWA is changed by using the diode switch technique. Each case has a different angle of the main beam, and the radiation pattern change by changing the switch diode cases. When the change of lumped element of the microstrip line leads to a change in the main beam direction, this varying depends on the value of the lumped element (inductance, capacitance, and resistance) [15]-[18]. According to the short and open circuit for the microstrip line, the microstrip leaky-wave antenna is loaded by the stop lumped element to control the radiation pattern. One of the most important control techniques is using the varactor diode with a microstrip line and using the biasing voltage to control the varactor diode, leading to the head of the main beam direction [19], [20]. The space between the stub loads it's very effective for the direction of the main beam. The composite right left hand of microstrip leaky-wave antenna using the slots for controlling the pattern by altering the operation frequency [21]-[23]. Archbold et al. has used the transverse resonance in [24] for determining the suitable capacitance to achieve the main beam at a demanded angle. Over the operating frequency range, the main beam of (HW-MLWA) was steered at a fixed frequency. Using lumped capacitors to load the microstrip edge, the beam has been pointed in the wanted direction.

In this article, the half-width microstrip leaky-wave antenna was proposed to control the radiation pattern by using the zigzag slots technique. By changing the operation frequency, the direction of the main beam has been altered. Thus, a change in the operating frequency leads to a change in the antenna reactance instead of variation in the radiation pattern power direction.

\section{CONFIGURATION OF ANTENNA}

The proposed half-width microstrip LWA is shown in Figure 1(a) (perspective view). This design is modified for half leaky width wave with zigzag unit cell slots. The Rogers RT5880 uses as substrate and tan $(\delta)=0.00090$, and $\left(\varepsilon_{\mathrm{r}}=2.2\right)$. The length $(\mathrm{L})$ of the substrate is $230 \mathrm{~mm}\left(3.26 \lambda_{\mathrm{o}}\right)$, and the width of the substrate is $45 \mathrm{~mm}\left(0.71 \lambda_{\mathrm{o}}\right)$. The thickness of Rogers RT5880 is $1.575 \mathrm{~mm}$, and the wavelength $\left(\lambda_{\mathrm{o}}\right)$ for the free space is $4 \mathrm{GHz}$ for the application of the $\mathrm{C}$ band. The dimensions of the microstrip patch are $180 \mathrm{~mm}$ for the length of the microstrip line and $10 \mathrm{~mm}$ for the width of the microstrip patch. The proposed HW-MLWA is fed from one side by using a stander SMA connector, as shown in Figure 1(b) and 1(c). The feed line length $l_{p s}$ and width $w_{f l}$ are (4.54 and 4.1) mm, respectively. This type of connector has low losses at a higher frequency, and the impedance of this connector is very low [25], [26]. The other side of the microstrip line is terminated by the lumped element using the $50 \mathrm{ohms}$ loaded to prevent any electromagnetic reflection. On the other hand, to get good impedance between connector and microstrip line. The proposed design of the microstrip line is connected with the ground by a vias connector in order to force the microstrip line for working in the first higher-order mode for electromagnetic wave [27] the dimension of via according to this equations.

$$
P>0.2 \lambda_{o}, \frac{P}{D} \leq 0.5
$$

The space between every two vias $(\mathrm{P})$ is $2 \mathrm{~mm}$, and the diameter of vias is $0.9 \mathrm{~mm}$. Therefore, the distance between the first and the edge line towards the fed port (S) is $3 \mathrm{~mm}$. This space is significant to reflect the electromagnetic wave towards the microstrip line. The input impedance of HW-MLWA can be calculated by using (3)-(5). The technical method is implementing electronic control for the maximum radiation pattern of the LWA according to the circular waveguide, which has a longitudinal slot.

$$
\begin{aligned}
& Z_{i n}=Z_{w}\left[\frac{Z_{L}+Z_{w} \tanh (\gamma L)}{Z_{w}+Z_{L} \tanh (\gamma L)}\right] \\
& Z_{w}=8 Z_{o} \sin ^{2}\left(\frac{\pi y}{W_{e f f}}\right) \frac{k_{o} h}{k W_{e f f}} \sqrt{\frac{\mu_{r}}{\varepsilon_{r}}} \\
& Q_{f}=\frac{1.23}{\left[1+0.12\left(\left(\frac{l_{u}}{w_{p}}\right)-1\right)^{0.9}\right]}
\end{aligned}
$$

The leaky-wave antenna contains a round, dielectric-filled waveguide with a longitudinal slot, symmetrically tapering from the center to the edges, an absorbing load placed directly short-circuited end of the waveguide, open ring electrodes, thin compared to the operating wavelength, placed inside the waveguide on equal. 


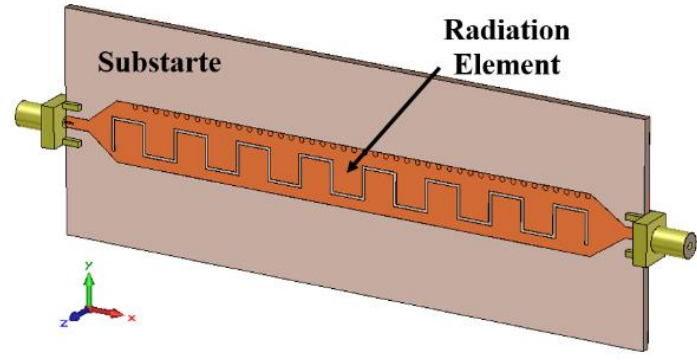

(a)

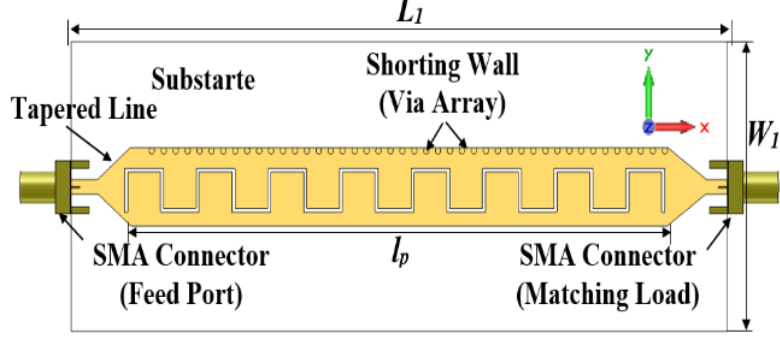

(b)

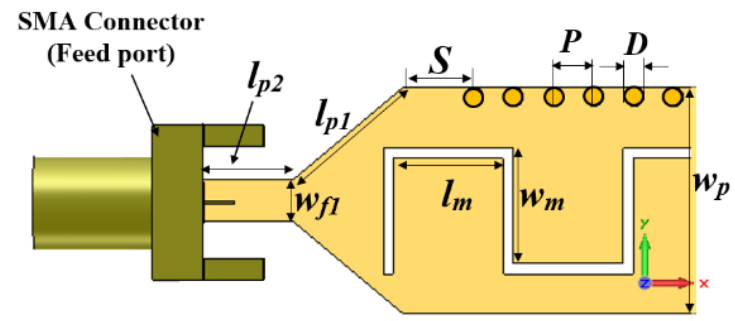

Taperd Line

(c)

Figure 1. Half-width microstrip LWA; (a) perspective view, (b) top view matching load with slots, (c) port and slot dimensions

\section{RESULTS AND DISCUSSION}

The controlling of the main beam is dependent on the sweeping operating frequency. Each state of the frequency leads to change the reactance of the profile microstrip antenna, then change the phase constant of the microstrip leaky-wave antenna (half-width), which change the main beam according to (1). For example, the state 1 at $4 \mathrm{GHz}$, the main beam direction is $19^{\circ}$, and the directivity is $11 \mathrm{~dB}$, while state 2 , when the sweeping frequency from 5 to $4.1 \mathrm{GHz}$, the direction is equal to $25^{\circ}$, and the directivity is $11.5 \mathrm{~dB}$. In-state 3 , the directivity is increased when the operation frequency increased. Also, the radiation pattern direction is $29^{\circ}$. The state 4, 5 and 6, the directivity increased with the operating frequency [28], [29]. In-state 7, the directivity was decreased because the radiation power loss in the endfire of the microstrip line is evident in Table 1 and Figure 2. An etched slot has been placed in the HW-MLWA radiation element for realizing a wideband antenna. The slots have a negligible effect on the radiation pattern and do not raise the antenna size. The slot shape and position have to be appropriate on the LWA. Hence, the meandering slot equivalent circuit has inductance, and it is a series joined to another shunt inductance.

Table 1. Selected seven case of sweeping frequency

\begin{tabular}{cccccc}
\hline State No. & $\begin{array}{c}\text { Sweeping operating } \\
\text { frequency (GHz) }\end{array}$ & $\begin{array}{c}\text { Main Beam Direction } \\
\text { (Degree) without } \\
\text { meandering slots }\end{array}$ & $\begin{array}{c}\text { Main Beam } \\
\text { Direction (Degree) }\end{array}$ & $\begin{array}{c}\text { Directivity (dB) without } \\
\text { meandering slots }\end{array}$ & Directivity (dB) \\
\hline 1 & 4 & $17^{\circ}$ & $19^{\circ}$ & 10 & 11 \\
2 & 4.1 & $22^{\circ}$ & $25^{\circ}$ & 10.3 & 11.5 \\
3 & 4.2 & $25^{\circ}$ & $29^{\circ}$ & 11 & 12.6 \\
4 & 4.3 & $27^{\circ}$ & $30^{\circ}$ & 11.4 & 13 \\
5 & 4.4 & $29^{\circ}$ & $33^{\circ}$ & 11.9 & 13 \\
6 & 4.5 & $35^{\circ}$ & $39^{\circ}$ & 12.4 & 12.4 \\
7 & 4.6 & $41^{\circ}$ & $45^{\circ}$ & 11.9 & \\
\hline
\end{tabular}

Int J Elec \& Comp Eng, Vol. 12, No. 1, February 2022: 392-398 
In Figure 3, the radiation pattern (main beam direction) of state 1 and 2 are $19^{\circ}$ and $25^{\circ}$ respectively. The simulation result according to $\mathrm{H}$ - plane and the phi is equal to zero. When microstrip LWAs are designed by analyzing the complex factors of characteristic impedance input, all the value of these parameters depends on the antenna's reactance profile.

The optimum values of parameter antenna by using the parametric study method. In-state 6 and 7, the radiation pattern is $39^{\circ}$ and $45^{\circ}$, respectively. The primary factor of the microstrip line is complex propagation constant change by changing the reactance between microstrip patch and ground plane. The electromagnetic file becomes zero between the patch microstrip line of the proposed antenna and the ground plane, that's means the antenna working in the first higher-order mode. The vias make a short circuit between the patch microstrip line of the leaky-wave antenna and the ground plane. According to phase constant, when getting the similar reactance of two cases that means to get the same main beam direction according to phase constant [30]-[33]. Each slot in the microstrip line led to increasing in the electric field then led to increasing the gain of the proposed antenna [34]. In Figure 4 the simulation of realized gain with the main beam direction-the recognized gain decrease when the operation frequency increase. The maximum realized gain at $4.4 \mathrm{GHz}$ is equal to 13 $\mathrm{dB}$, and the minimum gain is $11 \mathrm{~dB}$ at $4 \mathrm{GHz}$. In Figure 4 the realized gain decrease with an increase in the degree of main beam direction. The electric field of the microstrip leaky-wave antenna is decreased in endfire, leading to reduced radiation power.

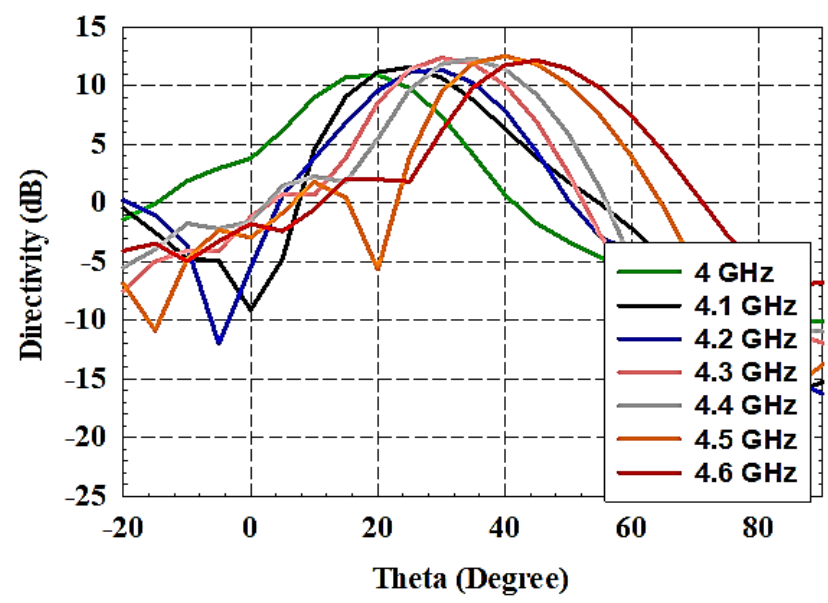

Figure 2. Directivity of suggested antenna with the main beam direction when sweeping frequency between $4 \mathrm{GHz}$ to $4.6 \mathrm{GHz}$
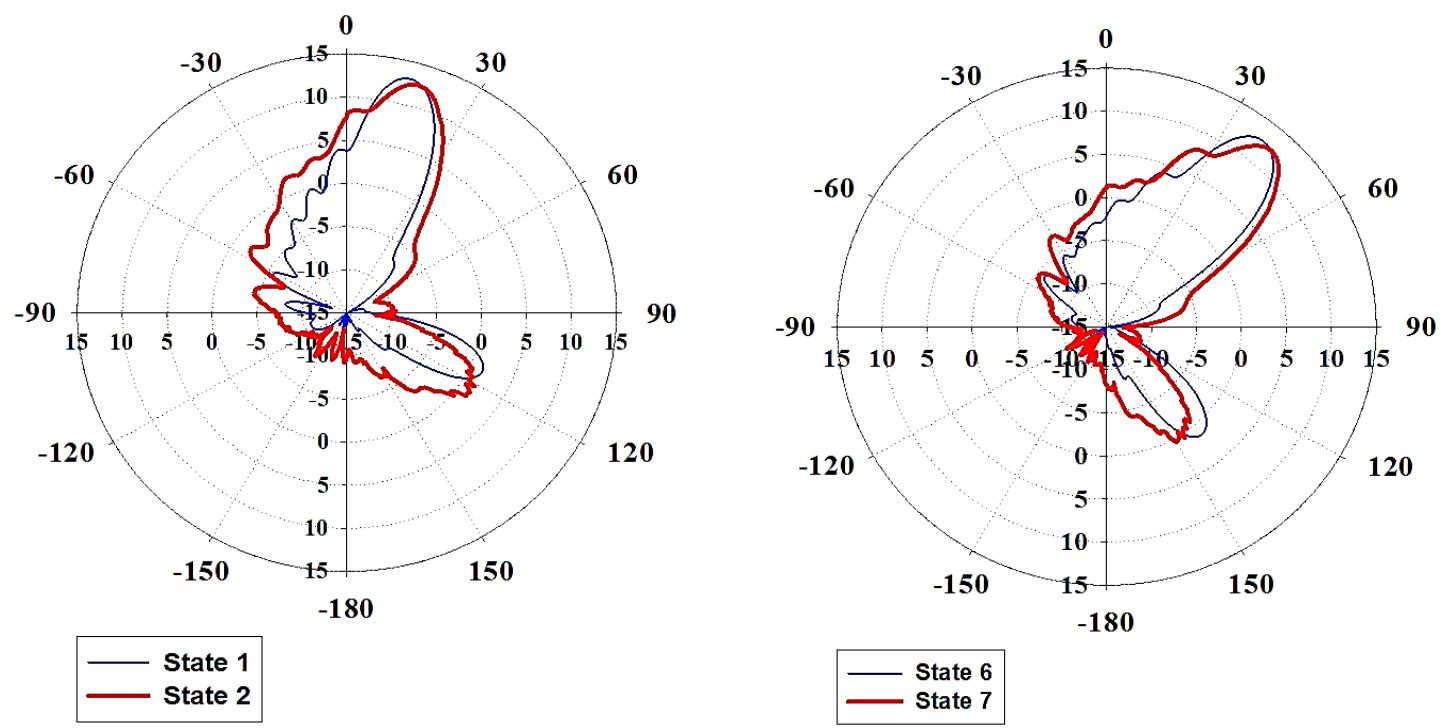

Figure 3. Radiation patterns of the proposed antenna on the H-plane (x-z plane) for states $1,2,6$, and $7(\mathrm{Phi}=0)$ 


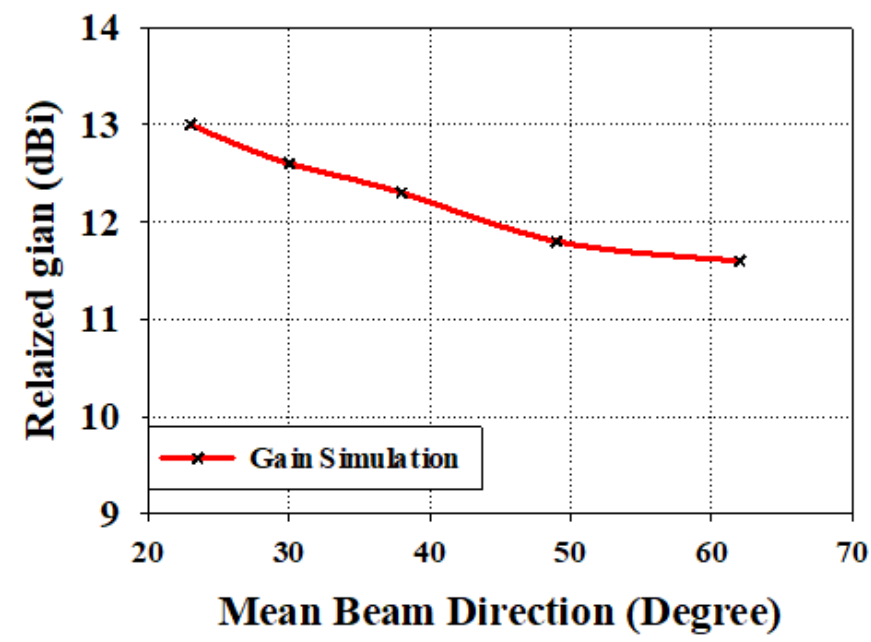

Figure 4. Simulated of proposed antenna gain of the half width microstrip LWA

The cross-polarization has been increased when the beam scans were neared to endfire [35], and beyond it to the forward direction, as shown in Figure 5. It is a central problem of a uniform HW-MLWA1 without using any slots. The radiation of the microstrip line is polarized in the $\mathrm{x}$-direction, while the polarization in the y-direction is for the radiation of the uniform HW-MLWA1 in the free edge. So, it is necessary to find an appropriate way to reduce cross-polarization while keeping the distance between slots. For minimizing the cross-polarization, a slop shaped slot has been added periodically as the meandered square. The cross-polarization level of uniform HW-MLWA1 and periodic HW-MLWA2 at state 1 are -9.45 and $-16.21 \mathrm{~dB}$ respectively, when the main lobe points close to the broadside. As a result, the maximum realized gain is equal to $13 \mathrm{~dB}$ for the beam direction at 33 . Thus, the radiation efficiency of microstrip LWA is changing in changing the direction of the main beam. In Figure 6, the maximum value of radiation efficiency has been achieved if the main lobe direction is close to broadside. However, the efficiency is decreased when nearing the main lobe to the endfire, which means the electromagnetic field is attenuate near the endfire.

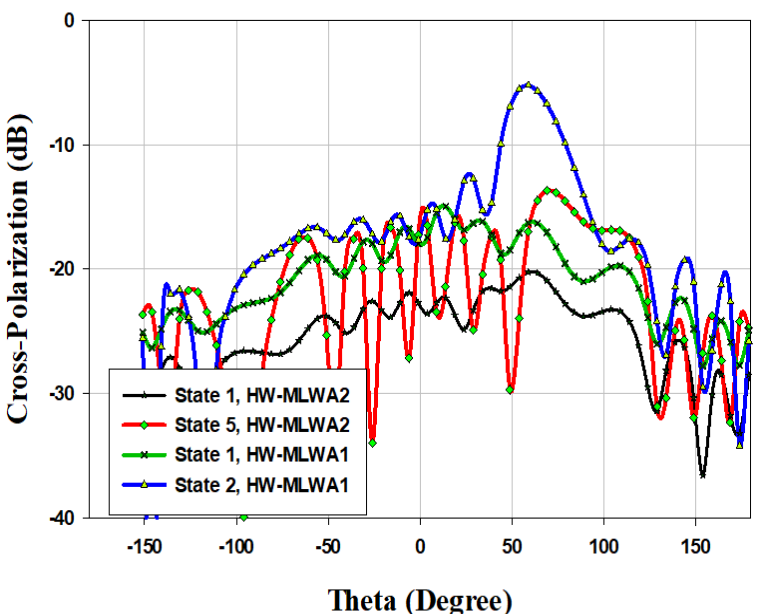

Figure 5. Cross polarization for the HW-MLWA1 and HW-MLWA2, concerning co-polarization level

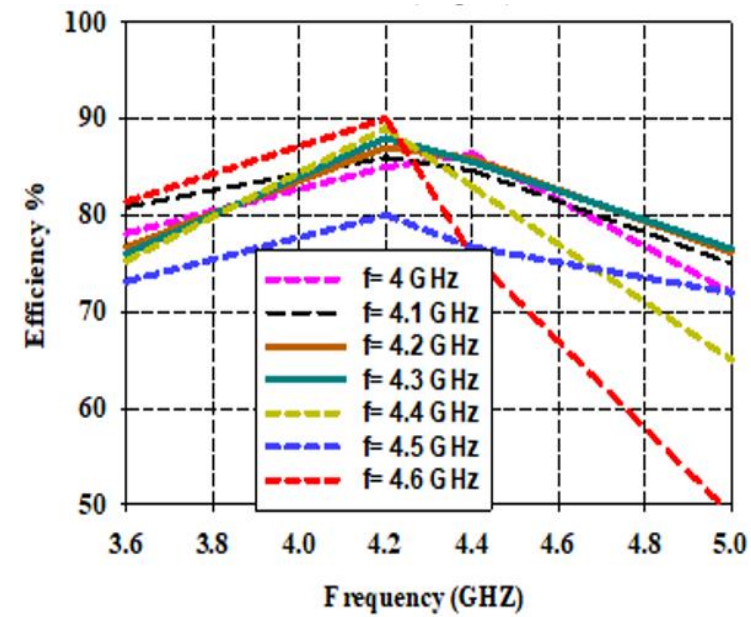

Figure 6. The efficiency of the suggested antenna for the seven states at $4.2 \mathrm{GHz}$

\section{CONCLUSION}

The practical phase constant in the half-width microstrip leaky-wave antenna is changed by changing the reactance profile of the microstrip antenna due to altering the operation frequency. The radiation power is increase by increasing the electric field in the endfire. The realized gain increase near broadside, the maximum value is 13 at $33^{\circ}$, and its decrease at endfire is equal to $11 \mathrm{~dB}$ at $4 \mathrm{GHz}$. The controlling radiation pattern by 
sweeping the frequency between $4 \mathrm{GHz}$ to $4.6 \mathrm{GHz}$ led to main beam direction scanning between $19^{\circ}$ to $45^{\circ}$. The proposed antenna is a non-reconfigurable periodic structure by using the unit cell is contain slots technique. The slots technique led to an increase in the electric field in the microstrip line, increasing the radiation power in the endfire. Thus, the proposed design provided control of the radiation pattern in the $\mathrm{C}$ band application.

\section{REFERENCES}

[1] H. Ermert, "Guiding and radiation characteristics of planar waveguides," 1978 8th European Microwave Conference, 1978, pp. 94-98, doi: 10.1109/EUMA.1978.332520.

[2] M. K. Abdulhameed et al., "Radiation control of microstrip patch antenna by using electromagnetic band gap," International Journal of Electronics and Communications (AË̈), vol. 110, 2019, Art. no. 152835, doi: 10.1016/j.aeue.2019.152835.

[3] Z. Zakaria, M. A. Mutalib, A. R. Othman, M. M. Ismail, M. S. M. Isa, and N. A. Zainuddin, "Suspended stripline structure (SSS) microwave bandpass filter with defected stripline structure (DSS)," Advanced science letters, vol. 20, no. 2, pp. 469-472, 2014, doi:10.1166/asl.2014.5350.

[4] K. D. Karmokar and K. P. Esselle, "Periodic U-slot-loaded dual-band half-width microstrip leaky-wave antennas for forward and backward beam scanning," IEEE Transactions on Antennas and Propagation, vol. 63, no. 12, pp. 5372-5381, 2015, doi: 10.1109/TAP.2015.2490252.

[5] A. M. Dinar, A. S. M. Zain, and F. Salehuddin, "Comprehensive identification of sensitive and stable ISFET sensing layer high-k gate based on ISFET/electrolyte models," International Journal of Electrical and Computer Engineering (IJECE), vol. 9, no. 2, pp. 926-933, doi: 201910.11591/ijece.v9i2.pp926-933.

[6] M. K. Abdulhameed, M. S. M. Isa, Z. Zakaria, and M. K. Mohsen, "Controlling the radiation pattern of patch antenna using switchable EBG," TELKOMNIKA (Telecommunication Computing Electronics and Control), vol. 16, no. 5, pp. 2014-2022, 2018, doi: 10.12928/TELKOMNIKA.v16i5.10443.

[7] N. Nasimuddin, Z. N. Chen, and X. Qing, "Substrate integrated metamaterial-based leaky-wave antenna with improved boresight radiation bandwidth," IEEE Transactions on Antennas and Propagation, vol. 61, no. 7, pp. 3451-3457, 2013, doi: 10.1109/TAP.2013.2256094.

[8] A. M. Dinar, A. S. M. Zain, and F. Salehuddin, "utilizing of cmos isfet sensors in dna applications detection: a systematic review," Journal of Advanced Research in Dynamical and Control Systems, vol. 10, no. 4, pp. 569-581, 2018.

[9] Y. M. Zeain et al., "Design of a wideband strip helical antenna for 5G applications," Bulletin of Electrical Engineering and Informatics (BEEI), vol. 9, no. 5, pp. 1958-1963, 2020, doi: 10.11591/eei.v9i5.2055.

[10] A. J. A. Al-Gburi et al., "A miniaturised UWB FSS with stop-band characteristics for EM shielding applications," Przegląd Elektrotechniczny, vol. 8, no. 25, pp. 142-145, 2021, doi: 10.15199/48.2021.08.25.

[11] C. Jin and A. Alphones, "Leaky-wave radiation behavior from a double periodic composite right/left-handed substrate integrated waveguide," IEEE Transactions on Antennas and Propagation, vol. 60, no. 4, pp. 1727-1735, 2012, doi: 10.1109/TAP.2012.2186248.

[12] M. K. Abdulhameed et al, "Review of radiation pattern control characteristics for the microstrip antenna based on electromagnetic band gap (EBG)," Journal of Telecommunication, Electronic and Computer Engineering (JTEC), vol. 10, no. 3, pp. 129-140, 2018.

[13] A. J. A. Al-Gburi et. al., "High gain of UWB CPW-fed mercedes-shaped printed monopole antennas for UWB applications," Prz. Elektrotechniczny, vol. 5, pp. 70-73, 202, doi: 10.15199/48.2021.05.11.

[14] R. A. Alahnomi, Z. Zakaria, E. Ruslan, A. A. M. Bahar, and S. R. A. Rashid, "High sensitive microwave sensor based on symmetrical split ring resonator for material characterization," Microwave and Optical Technology Letters, vol. 58, no. 9, pp. 2106-2110, 2016, doi: 10.1002/mop.29979.

[15] M. K. Abdulhameed et al., "Novel design of triple-band EBG," TELKOMNIKA (Telecommunication Computing Electronics and Control), vol. 17, no. 4, pp. 1683-1691, 2019, doi: 10.12928/TELKOMNIKA.v17i4.31980.

[16] A. M. Dinar, A. S. M. Zain and F. Salehuddin, "insight of research on cmos image sensor in molecular diagnostics/detection: A systematic," Opción, vol. 34, no. 85, pp. 2737-2753, 2018.

[17] M. K. Abdulhameed, M. S. Kod, and A. J. A. Al-Gburi, "Enhancement of elevation angle for an array leaky-wave antenna," Przegląd Elektrotechniczny, vol. 8, no. 19, pp. 109-113, 2021, doi: 10.15199/48.2021.08.19.

[18] Z. Al Qadi, Y. Eltous, M. Abuzalata, and G. M. Qaryouti, "Detecting and counting minutiae in human fingerprint," Open Science Journal, vol. 5, no. 1, pp. 1-5, 2020, doi: 10.23954/osj.v5i1.2284.

[19] J. Liu, D. R. Jackson, and Y. Long, "Substrate integrated waveguide (SIW) leaky-wave antenna with transverse slots," IEEE Transactions on Antennas and Propagation, vol. 60, no. 1, pp. 20-29, 2012, doi: 10.1109/TAP.2011.2167910.

[20] I. M. Ibrahim, Z. Zakaria, and H. A. Bakar, "Parametric study of modified U-shaped split ring resonator structure dimension at ultra-wide-band monopole antenna," J. Telecommun. Electron. Comput. Eng, vol. 10, pp. 2-5, 2018

[21] J. Liu, D. R. Jackson, Y. Li, C. Zhang, and Y. Long, "Investigations of SIW leaky-wave antenna for endfire-radiation with narrow beam and sidelobe suppression," IEEE Transactions on Antennas and Propagation, vol. 62, no. 9, pp. 4489-4497, 2014, doi: 10.1109/TAP.2014.2336659.

[22] Nasimuddin, Z. N. Chen, and X. Qing, "Multilayered composite right/left-handed leaky-wave antenna with consistent gain," IEEE Transactions on Antennas and Propagation, vol. 60, no. 11, pp. 5056-5062, 2012, doi: 10.1109/TAP.2012.2207680.

[23] M. K Abdulhameed, M. S. M. Isa, Z. Zakaria, I. M. Ibrahim, and M. K. Mohsen, "Radiation pattern control of microstrip antenna in elevation and azimuth planes using EBG and pin diode," International Journal of Electrical and Computer Engineering (IJECE), vol. 9, no. 1, pp. 332-340, 2019, doi: 10.11591/ijece.v9i1.

[24] M. Archbold, E. J. Rothwell, L. C. Kempel, and S. W. Schneider, "Beam steering of a half-width microstrip leaky-wave antenna using edge loading," IEEE Antennas and Wireless Propagation Letters, vol. 9, pp. 203-206, 2010, doi: 10.1109/LAWP.2010.2045730.

[25] N. A. Zainuddin et al., "Design of wideband antenna for RF energy harvesting system," IEEE 2013 3rd International Conference on Instrumentation, Communications, Information Technology and Biomedical Engineering (ICICI-BME), 2013, pp. 162-166, doi: 10.1109/ICICI-BME.2013.6698485.

[26] R. A. A. Kamaruddin et al., "Return loss improvement of radial line slot array antennas on closed ring resonator structure at 28 GHz," Przeglad Elektrotechniczny," vol. 1, no. 5, pp. 67-71, 2021, doi: 10.15199/48.2021.05.10.

[27] A. J. A. Al-Gburi, I. Ibrahim, Z. Zakaria, and A. D. Khaleel, "Bandwidth and gain enhancement of ultra-wideband monopole antenna using MEBG structure," ARPN Journal of Engineering and Applied Sciences (JEAS), vol. 14, no. 10, pp. 3390-3393, 2019, doi: $10.36478 /$ jeasci.2019.3390.3393. 
[28] A. J. A. Al-Gburi et al., "A compact UWB FSS single layer with stopband properties for shielding applications," Przeglad Elektrotechniczny, vol. 2, no. 34, pp. 165-168, 2021, doi: 10.15199/48.2021.02.34.

[29] K. M. Mohsen, M. S. M. Isa, A. A. M. Isa, M. K. Abdulhameed, M. L. Attiah, and A. M. Dinar, "Enhancement of boresight radiation for leaky wave antenna array," TELKOMNIKA Telecommunication Computing Electronics and Control, vol. 17, no. 5, pp. 2179-2185, 2019, doi: 10.12928/TELKOMNIKA.v17i5.12631.

[30] H. H. Keriee, M. K. A. Rahim, N. A. Nayyef, Z. Zakaria, and A. Al-Gburi, "High gain antenna at $915 \mathrm{MHz}$ for off grid wireless networks," Bulletin of Electrical Engineering and Informatics (BEEI), vol. 9, no. 6, pp. 2449-2454, 2020, doi:10.11591/eei.v9i6.2192.2020.

[31] M. A. Dinar, A. S. M. Zain, and F. Salehuddin, "CMOS ISFET device for DNA sequencing: device compensation, application requirements and recommendations," International Journal of Applied Engineering Research, vol. 12, no. 21, pp. 11015-11028, 2017.

[32] M. Y. Zeain et al., "Design of helical antenna for next generation wireless communication," Prz. Elektrotechniczny, vol. 11, pp. 96-99, 2020, doi: 10.15199/48.2020.11.19.

[33] A. J. A. Al-gburi, M. I. Ibrahim, and Z. Zakaria, "Gain enhancement for whole ultra-wideband frequencies of a microstrip patch antenna," Journal of Computational and Theoretical Nanoscience, vol. 17, no. 1-5, pp. 1469-1473, 2020, doi: 10.1166/jctn.2020.8827.

[34] S. Alani, Z. Zakaria, and H. Lago, "A new energy consumption technique for mobile ad hoc networks," International Journal of Electrical and Computer Engineering (IJECE), vol. 9, no. 5, pp. 41-47, 2019, doi: 10.11591/ijece.v9i5.pp4147-4153.

[35] Z. Zakaria et al., "Compact structure of band-pass filter integrated with defected microstrip structure (DMS) for wideband applications," The 8th European Conference on Antennas and Propagation (EuCAP 2014), 2014, pp. 2158-2162, doi: 10.1109/EuCAP.2014.6902236. 